\title{
PRECISION STUDIES OF NUCLEI
}

\author{
Final Report
}

September 1, 1994 - December 31, 1996

\author{
Paul E. Ulmer, Principal Investigator \\ Department of Physics \\ Old Dominion University \\ Norfolk, VA 23529
}

Report Date: February 1997

PREPARED FOR THE U.S. DEPARTMENT OF ENERGY

UNDER GRANT NUMBER DE-FG05-94ER40886

ODURF \#: 341361

(1) 


\section{DISCLAIMER}

This report was prepared as an account of work sponsored by an agency of the United States Government. Neither the United States Government nor any agency thereof, nor any of their employees, make any warranty, express or implied, or assumes any legal liability or responsibility for the accuracy, completeness, or usefulness of any information, apparatus, product, or process disclosed, or represents that its use would not infringe privately owned rights. Reference herein to any specific commercial product, process, or service by trade name, trademark, manufacturer, or otherwise does not necessarily constitute or imply its endorsement, recommendation, or favoring by the United States Government or any agency thereof. The views and opinions of authors expressed herein do not necessarily state or reflect those of the United States Government or any agency thereof. 


\section{DISCLAIMER}

Portions of this document may be illegible in electronic image products. Images are produced from the best available original document. 


\section{Abstract}

This grant covers the period Sept. 1, 1994 to Aug. 31, 1996 with an extension to Dec. 31, 1996. The main activities funded by this research grant include work on the TJNAF (formerly CEBAF) Hall A data analysis software project and other projects in Hall $A$ worked on by my graduate students. All of these projects are necessary for the functioning of Hall A and are therefore directly related to my Hall A research program.

\section{PROJECT DESCRIPTION}

The Hall $\mathrm{A}$ experimental equipment is still in the commissioning phase with the first experiment expected to be performed in May of 1997. My effort has focussed on software development, in particular on analyzing and calibrating the vertical drift chambers (VDCs) which will be used for particle tracking in the high resolution spectrometers. I have written a standalone program to determine calibration constants needed to obtain the ultimate position and angle resolution. High resolution performance will be paramount for much of the Hall A experimental program. In particular, I am spokesman on an experiment to separate the response functions in the $d\left(e, e^{\prime} p\right) n$ reaction. In order to make meaningful comparisons with theory, this experiment requires accurate determination of the cross sections and it will therefore be crucial to obtain the ultimate performance from the VDCs.

This grant has also provided partial support for two graduate students (Brian Diederich and Kathy McCormick). Brian has worked on several projects including calibrating the Hall $\mathrm{A}$ lead glass calorimeter (gain measurements using a $\mathrm{Xe} / \mathrm{N}$ flash lamp and fiber optic distribution system), constructing a gas distribution system for the Hall A drift chamber detectors and implementing a Fastbus readout system for ADCs and TDCs to be used for detector tests at ODU. Kathy has been involved in developing software to control the (LeCroy) high voltage system supplying the Hall A detector photomultipliers. This involves writing device drivers and a graphical user interface making it simple for users to adjust high voltages for a given experiment. All of the above projects (except the Fastbus readout project) are crucial for starting up the Hall A experimental program. The Fastbus readout project will be very useful for training students at ODU in the CEBAF data acquisition system (CODA).

The main experimental effort over the past two years has been the Bates focal plane polarimeter (FPP) program. The program involved measurement of the $\left(\vec{e}, e^{\prime} \vec{p}\right)$ and $\left(e, e^{\prime} \vec{p}\right)$ reactions and includes three experiments. The first experiment, on which $I$ am cospokesperson, involved measuring the $d\left(\vec{e}, e^{\prime} \vec{p}\right) n$ and $p\left(\vec{e}, e^{\prime} \vec{p}\right)$ reactions. This experiment addresses questions of the basic reaction mechanism in the deuteron and will provide a benchmark for the analogous $d\left(\vec{e}, e^{\prime} \vec{n}\right) p$ reaction which will determine the long sought after neutron electric form factor. The second experiment was a measurement of the induced polarization from the reaction ${ }^{12} \mathrm{C}\left(\mathrm{e}, \mathrm{e}^{\prime} \overrightarrow{\mathrm{p}}\right)$, a variant of an experiment on ${ }^{16} \mathrm{O}$ on which $\mathrm{I}$ am also cospokesperson. This experiment will help to quantify final state interaction effects as the induced polarization is identically zero in their absense. This knowledge is important input 
for understanding all (e,e'p) experiments and therefore critical for much of the CEBAF Hall A physics program. The third experiment involved measuring the $N \rightarrow \Delta$ transition via the $\mathrm{p}\left(\mathrm{e}, \mathrm{e}^{\prime} \overrightarrow{\mathrm{p}}\right) \pi^{0}$ and $\mathrm{p}\left(\mathrm{e}, \mathrm{e}^{\prime} \mathrm{p}\right) \pi^{0}$ reactions to address the question of deformation of the nucleon and delta wavefunctions. The data was collected from January 1995 to July 1995 and the analysis has been recently completed leading to seven $\mathrm{Ph}$.D. theses. Preliminary results of these experiments have been presented at the Amsterdam deuteron miniconference by W. Bertozzi in February 1996 (and at the 1995 APS/AAPT Conference in Washington, DC and at the 1995 Annual CEBAF Users Group Summer Workshop). Several papers are now being drafted and should be submitted for publication shortly. These experiments are directly related to my future research program in Hall $\mathrm{A}$ at CEBAF.

\section{EXPENSES}

Personnel: In addition to my summer salary, this grant provided support (stipends) for two graduate students who were involved in Hall A projects (see above).

Travel: This grant also covered travel expenses for me, for one of my graduate students (Brian Diederich) and for two trips by a postdoc (Liming Qin) who is shared by the ODU experimental nuclear physics group. Travel was mainly related to the above mentioned Bates experiments as well as conferences in Washington, DC (APS Conference), Williamsburg, VA (PANIC Conference) and Amsterdam (Deuteron Miniconference). In addition, I traveled to France (Saturne) to participate in the calibration of a neutron polarimeter which will be used at TJNAF (in Hall C) to measure the neutron electric form factor in an experiment on which I am collaborating (R. Madey, contact person). Finally, Brian Diederich attended a miniconference in the Netherlands on correlations in nuclei, which is directly related to his thesis experiment on $160\left(e, e^{\prime} p\right)$ (the first experiment planned to run in Hall $A$ at TJNAF).

Equipment: This grant supplied funds for a personal computer (with modem, printer and backup tape unit) for my use as well as an X-terminal for use by my graduate students. Finally, additional memory for an Alpha computer being used by the ODU nuclear physics group was also purchased with funds from this grant. 